\title{
RICARDO REIS E A DISCIPLINA DO VERSO
}

Fernando Morato ${ }^{1}$

RESUMO: Na poesia de Fernando Pessoa há constantes reflexões a respeito da identidade do próprio sujeito enunciante, exceto na obra de Ricardo Reis, justamente o heterônimo cuja produção foi mais constante ao longo dos anos. O último poema assinado por Reis parece dar uma pista importante a respeito da questão da identidade, da heteronímia e de como a própria obra do neoclássico parece apresentar uma resposta para essas questões.

PALAVRAS-CHAVE: Fernando Pessoa, Ricardo Reis, identidade, verso, reescrita.

ABSTRACT: In the poetry of Fernando Pessoa there is constant thinking about the identity of the subject except in the works by Ricardo Reis, who is the most constant writer among the beterônimos through the years. The last poem by Reis seems to give an important clue on the question of the identity, the heteronimia and on how the neoclassic work itself can look like an answer for those questions.

KEY-WO RDS: Fernando Pessoa, Ricardo Reis, identity, verse, rewriting.

No seu último ano de vida, Fernando Pessoa escreveu e datou apenas um poema em nome de Ricardo Reis. Desde 1914, surgimento do heterônimo, houve momentos de maior fertilidade, outros de menor intensidade (sempre tendo como referência os poemas datados), mas, com exceção de 1920, não houve um ano sem ser escrito pelo menos um poema em nome dele. Alberto Caeiro concentra sua produção entre os anos 1914-19, Álvaro de Campos tem momentos de silêncio no final dos anos 1910 e em meados dos 1920, mas Ricardo Reis escreve com constância e persistência sempre. Por isso o seu último poema merece alguma atenção:

Vivem em nós inúmeros;

Se penso ou sinto, ignoro

Quem é que pensa ou sente.

Sou somente o lugar

Onde se sente ou pensa.

Tenho mais almas que uma.

Há mais eus do que eu mesmo.

Existo todavia

Indiferente a todos.

Faço-os calar: eu falo.

Os impulsos cruzados

Do que sinto ou não sinto

Disputam em quem sou.

Ignoro-os. Nada ditam

A quem me sei: eu 'screvo.

(PESSOA, 2003, p 137).

\footnotetext{
${ }^{1}$ Mestrando do programa de Teo ria e História Literária da Unicamp
} 
Causa curiosidade, senão estranheza, a leitura deste derradeiro poema: a temática não parece a que tradicionalmente se associa a Ricardo Reis, lembrando mais a do ortônimo ou a de Álvaro de Campos, que mergulham na fragmentação do sujeito e reconhecem as dificuldades de autodefinição do eu. Uma afirmação como "Se penso ou sinto, ignoro/ Quem é que pensa ou sente" não está longe de "Sinto que sou ninguém salvo uma sombra/ De um vulto que não vejo e que me assombra,/ E em nada existo como a treva fria", de Fernando Pessoa, ele-mesmo (PESSOA, 1965, p. 129), e parece se afastar enormemente das afirmações de autocontrole que costumamos reconhecer como típicas do heterônimo neoclássico.

Entretanto, acreditamos que a temática da fragmentação do sujeito em Ricardo Reis, ainda mais no último texto autógrafo, indica uma linha de leitura interessante para a obra desse autor e poderia iluminar alguns aspectos da produção de Fernando Pessoa como um todo. Continuemos a acompanhar o poema. Após o reconhecimento do fato da multiplicação de personalidades, o texto toma uma direção diferente da habitual nos heterônimos mais afeitos à fragmentação do eu. Primeiro, o sujeito lírico se identifica, não com as vozes que falam através dele, mas com o lugar onde essas vozes se manifestam; o espaço de ocorrência das vozes se sobrepõe à sua própria ocorrência, esvaziando um pouco a substância dessas vozes em si e submetendo-as a um elemento externo a elas próprias. Voltaremos a este ponto mais adiante.

Depois, o sujeito lírico reforça sua indiferença às diversas vozes que o habitam, introduzindo na questão heteronímica um tema típico de Ricardo Reis, porém, em seguida, assume uma atitude nova: fazê-los calar. Movimento incomum no heterônimo neoclássico, que prefere a resistência, por assim dizer, passiva às forças que o assolam: "Não vale a pena/ Fazer um gesto" (PESSOA, 2003, p 28), "Logo que a vida me não canse, deixo/ Que a vida por mim passe/ Logo que eu fique o mesmo" (Id., p 64), "Abdica e sê Rei de ti mesmo.”(Id., p. 97) são expressões mais frequentemente encontradas ao longo das Odes do que afirmações assertivas como "Faço-os calar. Eu falo." Reforça e desdobra esse movimento a conclusão do poema, que realiza essa atitude assertiva no próprio ato que dá existência ao poema: "Nada ditam/ A quem me sei: eu 'screvo."

O controle das "almas mais que uma" se realiza através da fala que cala os "impulsos cruzados", mas essa fala se identifica (através do paralelismo criado pelo texto) com a escrita, uma escrita que se mostra, em associação com a fala, voluntária e controlada, realização e definição de um eu. É interessante notar que, nos poemas atribuídos a Ricardo 
Reis, ao mesmo tempo em que o impulso em relação à vida é constantemente cerceado e deixado de lado em favor da aceitação de uma lei maior que é exterior ao sujeito ("Quer gozemos, quer não gozemos, passamos como o rio.” [Id., p.33]), haja também, quase como a outra face da moeda, essa atitude consciente e voluntária de controle e disciplina em relação à escrita:

Ponho na altiva mente o fixo esforço

Da altura, è̀ sorte deixo,

$\mathrm{E}$ as suas leis, o verso;

Que, quanto é alto e régio o pensamento,

Súbita a frase o busca

E o 'scravo ritmo o serve.

Este controle consciente da escrita em Ricardo Reis era evidente para o próprio Fernando Pessoa. Das obras em prosa que estavam sendo preparadas pelo poeta para a publicação dos poemas dos heterônimos, consta uma crítica de Álvaro de Campos a esse respeito. Comentando o poema acima ("Ponho na altiva mente"), Campos se mostra incomodado com a necessidade que o colega tem de se submeter a um elemento "artificial”:

Não concebo, porém, que as emoções, nem mesmo as do Reis, sejam universalmente obrigadas a odes sáficas ou alcaicas, e que o Reis, quer diga a um rapaz que lhe não fuja, quer diga que tem pena de ter que morrer, o tenha forçosamente que fazer em frases súbditas que por duas vezes são mais compridas e por duas vezes mais curtas, e em ritmos escravos que não podem acompanhar as frases súbditas senão em dez sílabas para as duas primeiras, e em seis silabas as duas segundas, num graduar de passo desconcertante para a emoção. (PESSOA, 1995, p. 141).

Na controvérsia que surge entre Ricardo Reis e Álvaro de Campos, o neoclássico rebate a concepção de poesia do futurista e justifica sua adoção de versos, ritmos e formas da tradição clássica:

Um poema é a projecção de uma ideia em palavras através da emoção. A emoção não é a base da poesia: é tão somente o meio de que a ideia se serve para se reduzir a palavras./ Não vejo, entre a poesia e a prosa, a diferença fundamental, peculiar da própria disposição da mente, que Campos estabelece. Desde que se usa de palavras, usa-se de um instrumento ao mesmo tempo emotivo e intelectual. A palavra contém uma ideia e uma emoção. Por isso não há prosa, nem a mais rigidamente científica, que não ressume qualquer suco emotivo. Por isso não há exclamação, nem a mais abstractamente emotiva, que não implique ao menos o esboço de uma ideia. (...) A poesia é superior à prosa porque exprime, não um grau superior de emoção, mas, por contra, um grau superior do domínio dela, a subordinação do tumulto em que a emoção naturalmente se exprimiria (como verdadeiramente diz Campos) ao ritmo, à rima, à estrofe.(Id., p.134-44). 
A concepção da poesia não como uma maneira diferenciada de sentir ou de vivenciar a emoção, mas como exercício de palavra e, consequentemente, como um exercício de controle dos meios de expressão, recoloca justamente a preocupação central do poema "Vivem em nós inúmeros" e sugere que, em Ricardo Reis, a escrita neoclássica ultrapassa a mera opção estilística para aprofundar o próprio princípio da identidade do sujeito.

Da mesma forma que o sujeito lírico faz os "diversos impulsos cruzados" calarem através da fala/escrita, ele também subordina o "tumulto em que a emoção naturalmente se exprimiria" através da disciplina do ritmo, da rima e da estrofe. Estes elementos assumem, assim, papel maior do que o de meros elementos acessórios de escrita e passam a ser a própria essência da escrita poética. Retornando, então, ao poema, a disciplina de escrita assume um papel maior que a estruturação externa de uma voz que tem substância própria, anterior ao ato de escrever, e sugere que a fala/escrita é a própria substância da voz que se impõe sobre as demais.

Este ponto, de certa forma, foi sugerido por Maria Fernanda de Abreu (ABREU, 1985, pp. 62-72) ao analisar as duas versões da ode "Seguro assento na coluna firme," a que foi publicada na revista Athena, em 1924, e a que foi encontrada no espólio de Fernando Pessoa:

\section{Versão do Espólio}

Seguro Assento na coluna firme

Dos versos em que fico,

O criador interno movimento

Por quem fui autor deles

Passa, e eu sobrevivo, já não quem

Escreveu o que fez.

Chegada a hora, passarei também

$\mathrm{E}$ os versos, que não sentem

Serão a única restança posta

Nos capitéis do tempo.

A obra imortal excede o autor da obra;

E é menos dono dela

Quem a fez do que o tempo em que perdura.

Morremos a obra viva.

Assim os deuses esta nossa regem

Mortal e imortal vida;

Assim o Fado faz que eles a rejam.

Mas se assim é, é assim.

Aquele agudo interno movimento,

Por quem fui autor deles 
Primeiro passa, e eu, outro já do que era,

Póstumo substituo-me.

Chegada a hora, também serei menos

Que os versos permanentes.

E papel, ou papiro escrito e morto

Tem mais vida que a mente.

$\mathrm{Na}$ noite a sombra é mais igual à noite

Que o corpo que alumia.

\section{Versão publicada na revista Athena}

Seguro Assento na coluna firme

Dos versos em que fico,

Nem temo o influxo inúmero futuro

Dos tempos e do olvido;

Que a mente, quando, fixa, em si contempla

Os reflexos do mundo,

Deles se plasma torna, e à arte o mundo

Cria, que não a mente.

Assim na placa o externo instante grava

Seu ser, durando nela.

Para Abreu, as diferenças substanciais dos dois textos mostram a "evolução de personalidade" do sujeito lírico. Na primeira versão, mais longa, ele se demora nas considerações horacianas a respeito da permanência da obra em relação ao seu autor (o tópos da ode 30 do terceiro livro [HORÁCIO, 2003]), mas ao mesmo tempo insiste na finitude do eu como dado exterior ao seu controle, já que "deuses esta nossa regem/ Mortal e imortal vida". É possível reconhecer aqui, segundo a autora, um sujeito angustiado frente ao destino e que se conforma de maneira não muito convencida ("Mas se assim é, é assim") mesmo porque insiste no último dístico, na imagem da finitude e da sombra que se mistura à noite. Esta angústia visível desaparece na segunda versão, dando lugar à simples negação do medo da morte ou do olvido através da interiorização do movimento que o próprio mundo oferece e sua transformação em poesia: "Assim na placa o externo instante grava/ Seu ser, durando nela." A mudança de atitude diante do medo causado pelo fim da existência corresponde a uma mudança também de atitude frente à própria poesia, já que, num primeiro momento, o sujeito lírico se caracteriza como "autor" dos versos que escreve e, num segundo, quase como um instrumento em que o movimento do mundo exterior atua. (Lembremos: no poema "Vivem em nós inúmeros" o sujeito lírico não se apresenta como a voz que se alça frente às diversas que o habitam, mas como o lugar em que essas vozes se cruzam). 
Mais ainda, esta mudança de atitude diante da escrita e da ansiedade, nas diferentes versões do poema "Seguro assento na coluna firme", permite reconhecer uma mudança de postura filosófica diante da própria existência, revelando uma atitude que a autora chama de mais "empírica" frente à emoção que suscita a realização lírica. Ao invés de transformála imediatamente em poesia ("Aquele agudo interno movimento,/ Por quem fui autor deles"), passa a ser incorporada a outra prática que não a deixa extravasar absolutamente e, de certa maneira, faz o sujeito se controlar para viver maior integração com o conjunto do mundo que o cerca, resultando em mais autêntica obediência ao Fado. (Lembremos de novo: é a mesma atitude afirmada na controvérsia de Ricardo Reis com Álvaro de Campos).

O percurso descrito pela autora pode seguramente ser reconhecido como uma realização daquilo que Frederico Reis resumiu a respeito de seu irmão como "um esforço lúcido e disciplinado para obter uma calma qualquer” (PESSOA, 1995, p. 140), evidenciando um paralelo entre atitude pessoal e atitude artística.

Maria Fernanda de Abreu avança no reconhecimento de que esta mudança de postura de vida e de atitude filosófica frente ao mundo e ao reconhecimento do fim da vida se realiza também em uma mudança de enunciação. A segunda versão do poema "Seguro assento na coluna firme", além de consideravelmente mais curta, apresenta também "uma sintaxe contida, violenta, dura, sincopada, como os raciocínios do poeta" (ABREU, 1985). Aprendizado "de vida" que se materializa num equivalente maior controle de enunciação através da superação da espontaneidade com que o receio da morte era tratado.

É a aproximação desses dois movimentos (o controle das emoções e o controle da enunciação) que acreditamos merecer um pouco mais de atenção. Estamos diante de uma relação de mútuo reforço entre uma atitude filosófica e uma atitude estilística recorrente nos poemas de Ricardo Reis. Sabendo que a "segunda versão" do poema "Seguro assento na coluna firme" foi a que Fernando Pessoa optou por publicar (e como sendo a abertura do "Livro Primeiro" das Odes), é possível imaginar que a preservação das duas versões nos dê uma chave de leitura também anunciada teoricamente nos textos em prosa: estilo que corresponde a uma concepção/atitude filosófica.

Ricardo Reis, a personagem que constantemente retorna à pena de Fernando Pessoa, é também o heterônimo que mais comumente enuncia uma opção "positiva" de vida e uma opção de estilo. Alberto Caeiro alude com alguma frequência ao modo que adota para escrever e à relação dessa escrita com suas opções intelectuais de apagar as 
marcas de civilização, mas trata mais a respeito de sua prática de vida que de sua prática estilística. Como ambas se encontram no paradoxal esforço de ser o mais espontâneo possível, acabam por se identificar mais com a supressão das convenções, num esforço de escrita, por assim dizer, negativo:

Procuro dizer o que sinto

Sem pensar em que o sinto.

Procuro encostar as palavras à ideia

E não precisar dum corredor

Do pensamento para as palavras. (...)

Procuro despir-me do que aprendi,

Procuro esquecer-me do modo de lembrar que me ensinaram,

E raspar a tinta com que me pintaram os sentidos,

Desencaixotar as minhas emoções verdadeiras,

Desembrulhar-me e ser eu, não Alberto Caeiro,

Mas um animal humano que a Natureza produziu.

(PESSOA, 1965, p. 226).

O esforço de escrita/vivência não se aproxima de nenhum tipo de construção, mas, sim, da demolição de tudo o que vem de fora ao sujeito ("sem pensar", não precisar", “esquecer”, “raspar”, “desencaixotar”, “desembrulhar”) que não poupa nem a própria personalidade. Num movimento muito diferente do enunciado em "Vivem em nós inúmeros", Alberto Caeiro não reconhece essa identidade pessoal com nenhum tipo de organização ou disciplina, já que se define apenas como um "animal humano". Muito pelo contrário, a disciplina não constrói nada, limitando-se a destruir aquilo que contraria o "que a Natureza produziu".

Da maneira semelhante, em Álvaro de Campos, o esforço de identidade se caracteriza não pelo reconhecimento positivo de um limite, mas, sim, pelo transbordamento e pela indefinição e pela irregularidade:

Sim, sou eu, tal qual resultei de tudo,

Espécie de acessório ou sobresselente próprio, Arredores irregulares da minha emoção sincera, Sou eu aqui em mim, sou eu.

Quanto fui, quanto não fui, tudo isso eu sou.

Quanto quis, quanto não quis, tudo isso me forma.

Quanto amei ou deixei de amar é a minha saudade de mim.

(Id., p. 384).

É a identidade, mais uma vez, pela negação daquilo que poderia gerar um centro ou estruturação ao sujeito, seja personalidade, seja seleção de lembrança. A identidade de 
Ricardo Reis, por seu turno, constrói-se através de outro tipo de ação: o movimento ativo da própria escrita se desdobra em um estilo que cria a armadura com que o sujeito se sustenta. Essa armadura, desde o início, identifica-se com a tradição clássica:

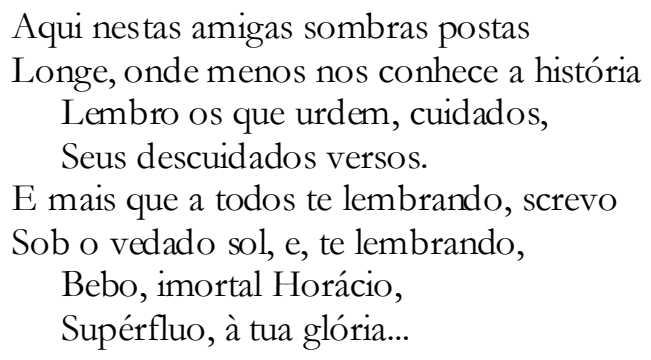

(PESSOA, 2003, p. 83).

A retomada explícita da referência anteriormente sugerida (através da "coluna firme dos versos”) a Horácio reforça a já bastante comentada filiação epicurista de Ricardo Reis. Mas aqui a insere através de duas imagens que dialogam com a leitura que estamos tentando empreender: "te lembrando, screvo" e "te lembrando/ Bebo." Escrever é uma prática que corresponde a uma disciplina de vida, aproveitada de maneira controlada nos prazeres que ela tem a oferecer. Do ponto de vista dos valores e das escolhas pessoais e morais, muito já se escreveu a respeito do que Ricardo Reis afirma, e não cremos que isso tenha muito a acrescentar no momento. Mas explorar a identidade entre a enunciação de controle e a escolha estilística pode ser interessante.

Deve-se acrescentar às observações feitas por Maria Fernanda de Abreu um outro aspecto importante da estética de Ricardo Reis que está em pleno acordo com tudo que já foi reconhecido até aqui: a concisão.

É um traço bastante característico da poética reisiana a concentração da frase e das imagens, muitas vezes adquirindo um tom sentencioso que a aproxima da máxima, formulação concisa e "acabada" de uma visão de mundo que se constrói menos como sistema, mas como entrecruzamento de diversos enunciados (DÉCHERY, 1994). Nas coletâneas de máximas dos moralistas franceses do século XVII, o conjunto de proposições vale mais que a proposição individual, apesar de ela ser um "átomo" autossuficiente. Não é muito diferente em Ricardo Reis, se lembrarmos que em quase nenhum ano de vida desde 1914, Fernando Pessoa deixou de escrever ao menos um poema como este heterônimo: é uma rede de enunciados que se vai montando ao longo do tempo, buscando sempre a fórmula. 
Para ser grande, sê inteiro: nada

Teu exagera ou exclui.

Sê todo em cada coisa. Põe quanto és

No mínimo que fazes.

Assim em cada lago a lua toda

Brilha, porque alta vive.

Fica evidente, ainda mais uma vez, a coincidência muito frequente, em Reis, da frase com a versificação que pode ser considerada a essência de seu método de escrita "aforística". Raras vezes um pensamento completo ultrapassa o limite das estrofes do poema (na maior parte dos casos, um dístico decassílabo seguido de um dístico hexassílabo). A estrofe, além de limite rítmico, é limite de pensamento, pois o enjambement, apesar de usado com frequência, raramente faz uma frase ultrapassar o limite estrófico (apenas em cinco poemas das Odes isso acontece). Cada poema é uma estrutura fechada em si, que se autossustenta na construção lapidar dentro de um esquema rítmico bastante regular: somente 28, dentre os 190 textos de Ricardo Reis, não são escritos com alternância de decassílabos e hexassílabos, e apenas 13 têm versos diferentes dessas duas medidas.

O movimento sintático, que nas duas versões de "Seguro assento na coluna firme" se tornou mais intrincado, aqui não se contorce tanto, mas justamente porque atingiu a concisão absoluta que a "lição moral" do poema exigia para se realizar. Entretanto, essa formulação se realiza em uma estrutura prosódica bastante firme, abusando das elisões e sinalefas. É a efetivação da proposta de "Que, quanto é alto e régio o pensamento,/ Súbita a frase o busca" encontrando a formulação lapidar.

A propósito da ideia de identidade entre o pensamento elevado e o estilo nobre, é importante lembrar que o caminho proposto por Reis é de que a frase busque o pensamento e a ele se adeque de maneira a que o enunciado surja de forma "natural". Não é o mesmo natural de Alberto Caeiro (que nega tudo o que não seja do "animal humano") ou de Álvaro de Campos (cumulando indiferentemente todas as vivências e experiências), mas uma concepção, por assim dizer, "clássica”, que naturaliza a regra e, principalmente, os limites.

É arte que não se basta em si, mas sem a qual o pensamento também não é suficiente. Na verdade, é a mesma busca que o Pseudo-Longino diz existir para se atingir o sublime:

No entanto, (...) mesmo nesse caso e mesmo se se trata de um dom mais do que de uma aquisição, apesar disso e na medida do possível, educar as almas em direção ao grande e torná-las sempre prenhes, se se pode assim dizer, de uma exaltação genuína./ De que maneira, dirás? Escrevi, em 
algum lugar: o sublime é o eco da grandeza de alma. Disso decorre que mesmo sem voz seja admirado às vezes o pensamento totalmente nu, em si mesmo, pela própria grandeza de alma, (...)/ Primeiramente, portanto, e preciso tomar isso como princípio: o verdadeiro orador não deve ter pensamento baixo e ignóbil. Pois não e possível que pessoas que destinam seus pensamentos e seus cuidados a preocupações vis e próprias de escravos, ao longo da vida, produzam alguma coisa espantosa e digna de qualquer época. Mas são grandes os discursos, como é normal, daqueles que são capazes de ter pensamentos que tenham peso./ Dessa forma, aos homens que tem os pensamentos mais altos acontecer a natureza sublime. (PSEUDO-LONGINO, 1996).

Ricardo Reis parece estar fazendo um esforço constante no sentido de assimilar a lição do retor grego, mas ampliando o escopo da atuação do sublime, já que este não parece se restringir aos "verdadeiros oradores" e "grandes discursos", mas se tornar uma prática ao alcance de toda e qualquer pessoa. A lição de "Para ser grande, sê inteiro" não é uma orientação meramente literária, como as discussões entabuladas com Álvaro de Campos, mas uma "lição de vida", mais à maneira de Alberto Caeiro. Entretanto, diferente do Mestre, Ricardo Reis, implica menos uma renovação de atitudes que a disciplina quase ascética de interiorizar limites para seus atos e sua escrita.

É justamente a questão dos limites que interessa. O que Ricardo Reis está propondo como atitude diante dos diversos eus que o habitam e suas diversas vozes é silenciá-los através de um discurso que, mesmo que não esteja claramente enunciado no poema "Vivem em nós inúmeros", é insinuado por toda a obra que até então se escreveu em seu nome: aceitação do Fado, indiferença frente ao mundo busca incessante da felicidade tranquila.

O poema enuncia todos esses temas tendo como ponto de partida justamente uma imagem emblemática da heteronímia, o que não é comum à obra de Ricardo Reis, nem poética nem em prosa. Composto em 13/XI/1935, é o último poema datado de Reis e um dos últimos escritos por Fernando Pessoa, menos de vinte dias antes de sua morte em 30/XI/1935.

"Testamento poético" de Ricardo Reis, ele marca com clareza a posição de sua prática frente ao fenômeno da heteronímia, identificando-se com uma disciplina que, no momento, limita-se a enunciar-se enquanto "escrita", mas que traz em seu bojo todas as implicações que procuramos acompanhar aqui. Mesmo que Ricardo Reis continue sendo uma figura construída por uma pessoa fisicamente existente, acompanhar o desenvolvimento e construção de uma "personalidade de palavras" evidencia a identidade 
que se molda através das escolhas enuciativas (falo/screvo) que são, no fundo, a matéria de todo escritor. No fim, o que perdura é a "coluna firme/ dos versos em que fico."

\section{BIBLIOGRAFIA}

ABREU, Maria Fernanda de. "Sobre uma ode de Ricardo Reis/ Duas versões ou dois poemas?”. Coloquio/Letras, n. 88, Nov. 1985, pp. 67-72.

COELHO, Jacinto Prado. Diversidade e unidade em Fernando Pessoa. Lisboa: Verbo, 1969.

DÉCHERY, Laurent. "Réflexions sur l'aphorisme et la maxime à l'âge classique", in The Romance Quaterly. Washington, vol. 42, n. 4, 1994.

HORÁCIO. Odes. Sem tradutor. Lisboa: Casa Rolland, s. d.

HORÁCIO. Odes e epodos. Trad. Bento Prado de Almeida Ferraz, org. Anna Lia Amaral de Almeida Prado. São Paulo: Martins Fontes, 2003.

LIND, Georg Rudolf. Estudos sobre Fernando Pessoa. Lisboa: Imprensa Nacional/Casa da Moeda, 1981.

MORAES, João Quartim de. Epicurn, as Luzes da ética. São Paulo: Moderna, 1998.

OSAKABE, Haquira. Fernando Pessoa, resposta à decadência. São Paulo: Criar, 2002.

PERRONE-MOISES, Leila. Fernando Pessoa, aquém do eu, além do outro. São Paulo: Martins Fontes, 1982.

PESSOA, Fernando. Obras em prosa. Organização, introdução e notas de Cleonice Berardinelli. Rio de Janeiro: Aguilar, 1995 (primeira edição, 1974).

Obra Poética. Organização, introdução e notas de Maria Aliets Galhoz. Rio de Janeiro: Aguilar, 1965.

Poesia de Ricardo Reis. Edição de Manuela Parreira da Silva. Lisboa: Assírio e Alvim, 2000.

PSEUDO-LONGINO. Do sublime. Trad. Filomena Hirata. São Paulo: Martins Fontes, 1996.

REBELO, Luís de Sousa. "Fernando Pessoa e a tradição clássica", in A tradição clássica na literatura portuguesa. Lisboa, Livros Horizonte, 1982.

RODITI, Georges. Espirito de perfeição. Trad. Júlio Castañon Guimarães. Rio de Janeiro, Imago, 1990.

TABUCCHI, Antonio. Pessoana minima. Lisboa: Imprensa Nacional/Casa da Moeda, 1984. 